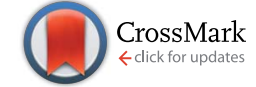

Cite this: RSC Adv., 2017, 7, 14528

\title{
Strategies for fast ion transport in electrochemical capacitor electrolytes from diffusion coefficients, ionic conductivity, viscosity, density and interaction energies based on HSAB theory $\uparrow$
}

\author{
Morihiro Saito, ${ }^{\text {*a }}$ Satoru Kawaharasaki, ${ }^{a}$ Kensuke Ito, ${ }^{a}$ Shinya Yamada, ${ }^{a}$ \\ Kikuko Hayamizu ${ }^{\text {b }}$ and Shiro Sekic
}

To elucidate factors affecting ion transport in capacitor electrolytes, five propylene carbonate (PC) electrolytes were prepared, each of which includes a salt $\left(\left(\mathrm{C}_{2} \mathrm{H}_{5}\right)_{4} \mathrm{NBF}_{4},\left(\mathrm{C}_{2} \mathrm{H}_{5}\right)_{4} \mathrm{NPF}_{6},\left(\mathrm{C}_{2} \mathrm{H}_{5}\right)_{4} \mathrm{NSO}_{3} \mathrm{CF}_{3}\right.$, $\left(\mathrm{C}_{2} \mathrm{H}_{5}\right)_{3} \mathrm{CH}_{3} \mathrm{NBF}_{4}$ and $\left.\mathrm{LiBF}_{4}\right)$. In addition to conventional bulk parameters such as ionic conductivity $(\sigma)$, viscosity $(\eta)$ and density $(\rho)$, self-diffusion coefficients $(D)$ of the cation, anion and PC were measured by pulsed-gradient spin-echo (PGSE) NMR. Interaction energies $(\Delta E)$ were calculated by density function theory calculations based on Hard and Soft Acids and Bases (HSAB) theory for cation-anion (salt dissociation) and solvent-cation/anion (solvation). $\Delta E$ values are related to the salt dissociation and solvation, which affect ion diffusion radii formed by solvation and/or ion pairs. The calculated solvation $\Delta E$ values were small (around $0.30 \mathrm{eV}$ ) and salt dissociation energies were also small. For comparison, the $\Delta E$ value for $\mathrm{PC}-\mathrm{Li}^{+}$interaction was larger than that for ammonium cations, because of strong $\mathrm{Li}^{+}$ Lewis acidity. Ammonium salts are highly dissociated and each ion forms a weakly solvated structure, which is quite different from $\mathrm{Li}^{+}$electrolytes. Weak solvation for the cation and anion in the ammonium salts are important in enhancing fast ion transfer and electrode reactions in capacitor devices.

Received 11th January 2017

Accepted 24th February 2017

DOI: $10.1039 / c 7 r a 00455 a$

rsc.li/rsc-advances electrodes are used. In recent years, due to the requirements for increased energy density of EDLCs, lithium ion capacitors (LICs), including faradaic-reaction NEs using graphite or hard carbon, have been intensively developed to overcome the low energy density limitation of EDLCs. ${ }^{6-11}$ Many researchers have evaluated the viscosity $\eta$, ionic conductivity $\sigma$ and density $\rho$ of electrolyte solutions, together with their electrochemical stability (potential window). ${ }^{12-15}$ Dielectric constants of solvents and degree of dissociation $\alpha$ of salts were also investigated to evaluate the solubility and dissociation of salts in these electrolytes. ${ }^{15,16}$ These physical parameters are important and useful for the design of suitable electrolytes for EDLCs and LICs. Physical parameters provide understanding of the macroscopic behaviours of electrolytes; however, to design new electrolyte systems for next-generation capacitors, more direct microscopic information is necessary, such as individual transport rates of ions and solvent, and their relationships with interaction energies between the components of the capacitor electrolytes.

This study targeted four electrolytes used in EDLCs and one electrolyte comprising a lithium salt used for LICs. Fig. 1 shows the chemical structures of cations and anions in the salts used in this study. We measured individual self-diffusion coefficients $D$ of the ions and solvent in these capacitor electrolytes by pulsed gradient spin-echo nuclear magnetic resonance (PGSENMR), together with conventional physical properties, i.e.,
${ }^{a}$ Department of Applied Chemistry, Faculty of Engineering, Tokyo University of Agriculture \& Technology, 2-24-16 Naka-cho, Koganei-shi, Tokyo 184-8588, Japan. E-mail: mosaito@cc.tuat.ac.jp; Fax: +81-42-388-7095; Tel: +81-42-388-7095

${ }^{b}$ Institute of Applied Physics, University of Tsukuba, 1-1-1 Tennoudai, Tsukuba, Ibaraki 305-8573, Japan

${ }^{c}$ Materials Science Research Laboratory, Central Research Institute of Electric Power Industry (CRIEPI), 2-6-1 Nagasaka, Yokosuka-shi, Kanagawa 240-0196, Japan

$\dagger$ Electronic supplementary information (ESI) available. See DOI: 10.1039/c7ra00455a 
Cations

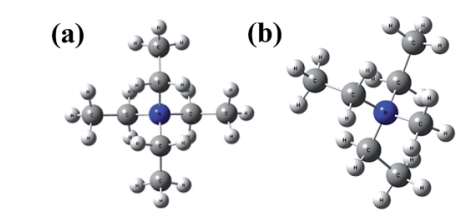

(c)

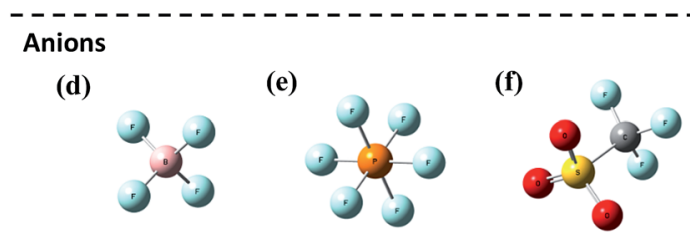

Fig. 1 Chemical structures of the cations and anions used in this study, as optimized by DFT calculation using a basis set of B3LYP/6$311+\mathrm{G} * * / / \mathrm{HF} / 3-21 \mathrm{G}$. (a) $\left(\mathrm{C}_{2} \mathrm{H}_{5}\right)_{4} \mathrm{~N}\left(\mathrm{TEA}^{+}\right)$, (b) $\left(\mathrm{C}_{2} \mathrm{H}_{5}\right)_{3} \mathrm{CH}_{3} \mathrm{~N}\left(\mathrm{TEMA}^{+}\right)$, (c) $\mathrm{Li}^{+}$, (d) $\mathrm{BF}_{4}{ }^{-}$, (e) $\mathrm{PF}_{6}{ }^{-}$and (f) $\mathrm{CF}_{3} \mathrm{SO}_{3}\left(\mathrm{OTf}^{-}\right.$).

ionic conductivity $\sigma$, viscosity $\eta$ and density $d$, of the electrolytes, and discuss these with respect to ion transport behaviour. The relationships between the $D$ values and the other conventional properties are analysed and discussed from the viewpoint of mobility and number of carrier ions in the electrolytes. To elucidate the relationship between the interactions between the chemical species and ion transport behaviour in the electrolytes, we also estimated the interaction energies between the cation-anion, propylene carbonate (PC)-cation and $\mathrm{PC}-$ anion by density function theory (DFT) calculation based on the Hard and Soft Acids and Bases (HSAB) theory ${ }^{17-19}$ for each electrolyte.

\section{Experimental}

We used five different $1.0 \mathrm{M}\left(\mathrm{mol} \mathrm{L}^{-1}\right)$ electrolyte solutions of ammonium salts, i.e., $\left(\mathrm{C}_{2} \mathrm{H}_{5}\right)_{4} \mathrm{NBF}_{4}\left(\mathrm{TEABF}_{4}\right.$, Kishida Chemical Co., Ltd.), $\left(\mathrm{C}_{2} \mathrm{H}_{5}\right)_{4} \mathrm{NPF}_{6}$ (TEAPF 6 , Aldrich), $\left(\mathrm{C}_{2} \mathrm{H}_{5}\right)_{4} \mathrm{NSO}_{3} \mathrm{CF}_{3}$ (TEAOTf, Wako Pure Chemicals), $\left(\mathrm{C}_{2} \mathrm{H}_{5}\right)_{3} \mathrm{CH}_{3} \mathrm{NBF}_{4}$ (TEMABF ${ }_{4}$, Tokyo Chemical Industry Co., Ltd.) and $\mathrm{LiBF}_{4}$ (Kishida Chemical Co., Ltd.) in propylene carbonate (PC, battery grade, Wako Pure Chemicals). Prepared samples were stored in an Ar-filled dry box (VAC, NEXUS II).

Ionic conductivity $\sigma$ of the electrolytes was measured in hermetically sealed cells [stainless steel (SUS)/electrolyte/SUS] and determined by complex impedance using an AC impedance analyser (Bio-Logic VSP, $200 \mathrm{kHz}$ to $50 \mathrm{mHz}$; applied voltage: $10 \mathrm{mV}$ ) in the temperature range of 283 to $353 \mathrm{~K}$. The electrolytes were thermally equilibrated at each temperature for at least $90 \mathrm{~min}$ prior to the measurement.

The self-diffusion coefficients of the cation $\left({ }^{1} \mathrm{H}\right.$ or $\left.{ }^{7} \mathrm{Li}\right)$, anion $\left({ }^{19} \mathrm{~F}\right)$ and solvent $\mathrm{PC}\left({ }^{1} \mathrm{H}\right)$ in the electrolytes were measured by PGSE-NMR using a JEOL tunable pulsed-field gradient (PFG) probe and an amplifier with a $6.4 \mathrm{~T}$ wide-bore superconducting magnet $\left({ }^{1} \mathrm{H}\right.$ resonance: $270 \mathrm{MHz}$ ) between 353 and $253 \mathrm{~K}^{20-23}$ Each sample was prepared in an NMR microtube (BMS-005J, Shigemi, Tokyo) to a height less than $5 \mathrm{~mm}$ to prevent convection effects. The calibration of the PFG was made by $\mathrm{H}_{2} \mathrm{O}\left({ }^{1} \mathrm{H}\right.$ resonance) and $\mathrm{D}_{2} \mathrm{O}\left({ }^{2} \mathrm{H}\right.$ resonance). Measurements were made by setting the PFG strength to 0.84 to $1.3 \mathrm{~T} \mathrm{~m}^{-1}$ for ${ }^{1} \mathrm{H}$ and ${ }^{19} \mathrm{~F}$ and $2.5 \mathrm{~T} \mathrm{~m}^{-1}$ for ${ }^{7} \mathrm{Li}$ for varying duration times. The PFG interval $(\Delta)$ was set between 20 and $50 \mathrm{~ms}$, depending on temperature. The confirmation of the accuracy of the diffusion constant was carried out by obtaining the same value with different $\Delta$ 's.

Measurements of viscosity $\eta$ and density $\rho$ were carried out using a Stabinger-type viscometer (SVM3000G2, Anton Paar). The temperature was controlled in the range of 283 to $353 \mathrm{~K}$ at $10 \mathrm{~K}$ intervals while heating the samples.

The more quantitative cation-anion and PC-cation interactions were investigated by ab initio Hartree-Fock (HF) selfconsistent field molecular orbital calculation and DFT calculation performed by Gaussian 09 software. ${ }^{24}$ The geometries of the cations, anions and PC were optimized by DFT using the B3LYP form for the exchange-correlation function and the $6-311+\mathrm{G}^{* *}$ basis set after HF optimization with the 3-21G basis set. From results of the total electron energy of the ions and solvent, the cation-anion, PC-cation and PC-anion interaction energies were estimated by equations based on HSAB theory. ${ }^{17-19}$

\section{Results}

Fig. 2 shows the temperature dependences of $\sigma$ for the $1.0 \mathrm{M} \mathrm{PC}$ based electrolytes with (a) a common cation (TEA ${ }^{+}$) and different anions $\left(\mathrm{BF}_{4}{ }^{-}, \mathrm{PF}_{6}{ }^{-}\right.$and $\left.\mathrm{OTf}^{-}\right)$and (b) a common anion $\left(\mathrm{BF}_{4}^{-}\right)$and different cations $\left(\mathrm{TEA}^{+}\right.$, TEMA ${ }^{+}$and $\left.\mathrm{Li}^{+}\right)$. All plots veered slightly towards higher values, but approximately followed an Arrhenius-type plot. For the common cation, the ionic conductivity decreased in order of $\mathrm{TEABF}_{4}>\mathrm{TEAPF}_{6}>\mathrm{TEAOTf}$ across the entire temperature range from 283 to $353 \mathrm{~K}$. In contrast, for the common anion $\left(\mathrm{BF}_{4}^{-}\right)$, the ionic conductivity

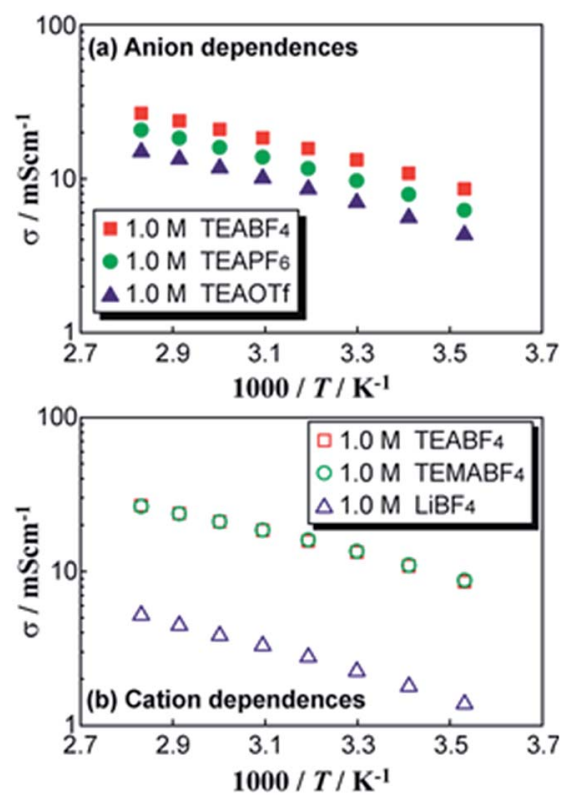

Fig. 2 Comparison of temperature dependences of ionic conductivity $\sigma$ for 1.0 M PC-based electrolytes with (a) a common cation $\left(\mathrm{TEA}^{+}\right.$) and different anions $\left(\mathrm{BF}_{4}{ }^{-}, \mathrm{PF}_{6}{ }^{-}\right.$and $\left.\mathrm{OTf}^{-}\right)$and $(\mathrm{b})$ a common anion $\left(\mathrm{BF}_{4}{ }^{-}\right)$ and different cations $\left(\mathrm{TEA}^{+}, \mathrm{TEMA}^{+}\right.$, and $\left.\mathrm{Li}^{+}\right)$. The values for $\mathrm{TEABF}_{4}$ and $\mathrm{TEMABF}_{4}$ almost overlap. 
changed in the order $\mathrm{TEMABF}_{4} \approx \mathrm{TEABF}_{4} \gg \mathrm{LiBF}_{4}$. The trend in ionic conductivity for the ammonium salt-based electrolytes was in good agreement with those reported by Ue et al., for a salt concentration of $0.65 \mathrm{M}$ at $298 \mathrm{~K}^{1}{ }^{1}$ The $\mathrm{LiBF}_{4}$-based electrolyte exhibited one order of magnitude lower $\sigma$ than the ammonium salt-based electrolytes. This difference will be described later.

The ionic conductivity of electrolytes was defined by eqn (1):

$$
\sigma=\sum_{j} q_{j} \times \mu_{j} \times n_{j}
$$

where $q, \mu$ and $n$ are the charge, mobility and number of carrier ions per specific volume, respectively; the suffix $j$ corresponds to the ammonium cations and anions. Ionic conductivity of electrolytes depends on (i) mobility and (ii) number of carrier ions per specific volume. Here, to consider the mobility $\mu$ of each carrier ion, we separately measured the $D$ values of the cation, anion and PC solvent by PGSE-NMR. Typical Arrhenius-type plots for $1.0 \mathrm{M}$ PC-based electrolytes containing $\mathrm{TEABF}_{4}$ and $\mathrm{TEAPF}_{6}$ are shown in Fig. 3. Except at high temperature, the diffusion constants of $\mathrm{TEABF}_{4}$ are larger than those of $\mathrm{TEAPF}_{6}$; within the same electrolyte, $D_{\mathrm{PC}}>D_{\text {anion }}>D_{\mathrm{TEA}}$. Summaries of the data for the other electrolytes are shown in Tables $1(D)$ and $2(\eta)$ in ESI. $\dagger$ For a single electrolyte, the order of the $D$ values was $\mathrm{PC}>$ anion $\left(\mathrm{BF}_{4}{ }^{-}, \mathrm{PF}_{6}{ }^{-}, \mathrm{TfO}^{-}\right)>$cation $\left(\mathrm{TEMA}^{+}, \mathrm{TEA}^{+}, \mathrm{Li}^{+}\right)$ across the entire temperature range evaluated. The temperature dependences essentially followed Arrhenius-type plots, indicating that the ions are transported by flow of the PC solvents and that the anions move more easily than the cations in these electrolytes. This trend was similar to those reported for electrolyte solutions for lithium ion batteries (LIB). ${ }^{20}$ The order of magnitude of $D$ for the four ammonium electrolytes and the lowest $D$ for a $1.0 \mathrm{M} \mathrm{LiBF}_{4} / \mathrm{PC}$ are in good agreement with the trend for $\sigma$. This indicates that $\sigma$ is significantly influenced by mobility $\mu$ of the carrier ions.

From the temperature dependences, the activation energies of $D$, i.e., $E_{\mathrm{a}}$, were estimated from the slopes of plots for the electrolyte systems, as shown in Table 1. For all electrolytes, including $\mathrm{LiBF}_{4} / \mathrm{PC}$, the $E_{\mathrm{a}}$ values were around $0.20 \mathrm{eV}$. The $E_{\mathrm{a}}$ values in these capacitor electrolytes were of the same scale as those of LIB electrolytes. This means that all chemical species are transported in a similar way in these electrolytes.

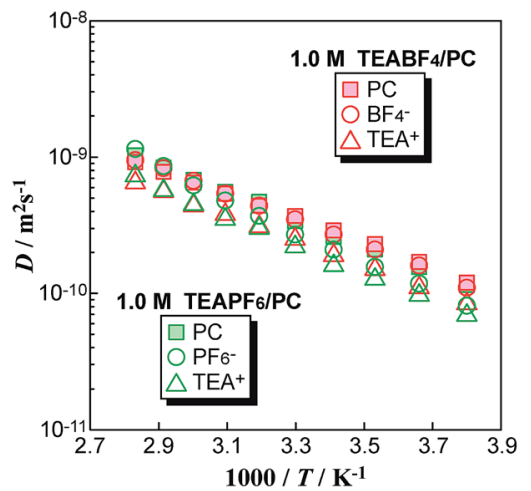

Fig. 3 Typical temperature dependences of self-diffusion coefficients $D$ for 1.0 M PC-based electrolytes containing $\mathrm{TEABF}_{4}$ and $\mathrm{TEAPF}_{6}$.
Table 1 Activation energies $E_{\mathrm{a}}$ from Arrhenius-type plots of $D$ for ions and $P C$ solvents and transference numbers of cations $t_{\text {cation }}$ at $303 \mathrm{~K}$ for 1.0 M PC-based electrolytes

\begin{tabular}{|c|c|c|c|c|}
\hline & $D_{\mathrm{PC}}$ & $D_{\text {cation }}$ & $D_{\text {anion }}$ & \\
\hline Electrolyte solution & $E_{\mathrm{a}} / \mathrm{eV}$ & $E_{\mathrm{a}} / \mathrm{eV}$ & $E_{\mathrm{a}} / \mathrm{eV}$ & $t_{\text {cation }}$ \\
\hline 1.0 $\mathrm{M} \mathrm{TEABF}_{4} / \mathrm{PC}$ & 0.18 & 0.20 & 0.18 & 0.42 \\
\hline 1.0 $\mathrm{M} \mathrm{TEAPF}_{6} / \mathrm{PC}$ & 0.20 & 0.23 & 0.21 & 0.45 \\
\hline 1.0 M TEAOTf/PC & 0.21 & 0.22 & 0.21 & 0.45 \\
\hline 1.0 $\mathrm{M} \mathrm{TEMABF}_{4} / \mathrm{PC}$ & 0.23 & 0.22 & 0.24 & 0.43 \\
\hline $1.0 \mathrm{M} \mathrm{LiBF}_{4} / \mathrm{PC}$ & 0.22 & 0.23 & 0.25 & 0.42 \\
\hline
\end{tabular}

From the $D$ values of the cations and anions, the apparent transference numbers of the cations were calculated by eqn (2), as follows:

$$
t_{\text {cation }}=D_{\text {cation }} /\left(D_{\text {cation }}+D_{\text {anion }}\right)
$$

The results at $303 \mathrm{~K}$ are shown in Table 1 (values for each $t_{\text {cation }}$ by temperature are summarized in $\mathrm{S} 1 \dagger$ ). All $t_{\text {cation values }}$ were around 0.40 , which is also similar to those reported for LIB electrolytes. ${ }^{20}$

In general, the $\sigma$ and $D$ values are strongly related to the viscosity of the electrolyte. The $D$ values of electrolyte solutions are known to increase with the decrease in viscosity. Fig. 4 shows the temperature dependences of $\eta^{-1}$ for 1.0 M PC-based electrolyte solutions in (a) a common $\mathrm{TEA}^{+}$cation with three anions and (b) a common $\mathrm{BF}_{4}{ }^{-}$anion with three cations. The $\eta^{-1}$ values for all electrolytes followed the trend of temperature dependences: TEABF $_{4}>$ TEAPF $_{6}>$ TEAOTf and TEMABF 4 T $\mathrm{TEABF}_{4} \gg \mathrm{LiBF}_{4}$. Because we used PC as a solvent in all
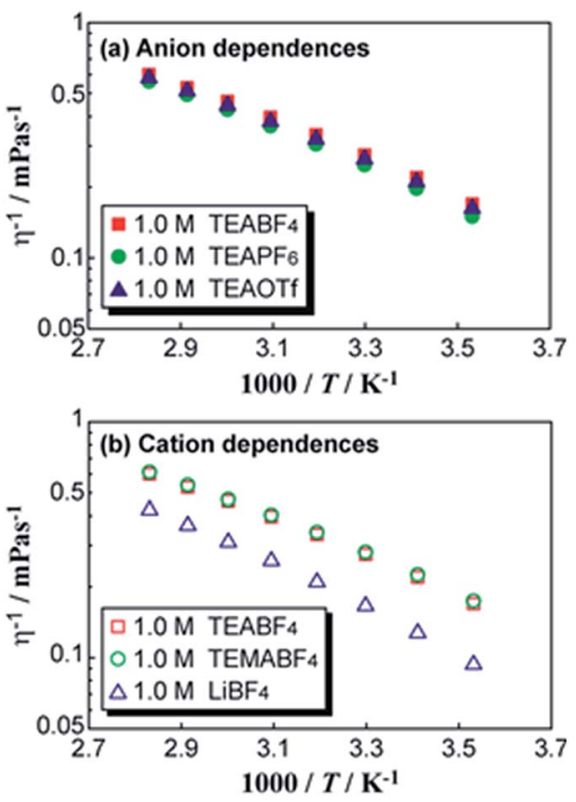

Fig. 4 Temperature dependences for inverse of viscosity $\eta^{-1}$ values for 1.0 M PC-based electrolytes in (a) a common $\mathrm{TEA}^{+}$with different anions and (b) a common $\mathrm{BF}_{4}{ }^{-}$with different cations. 

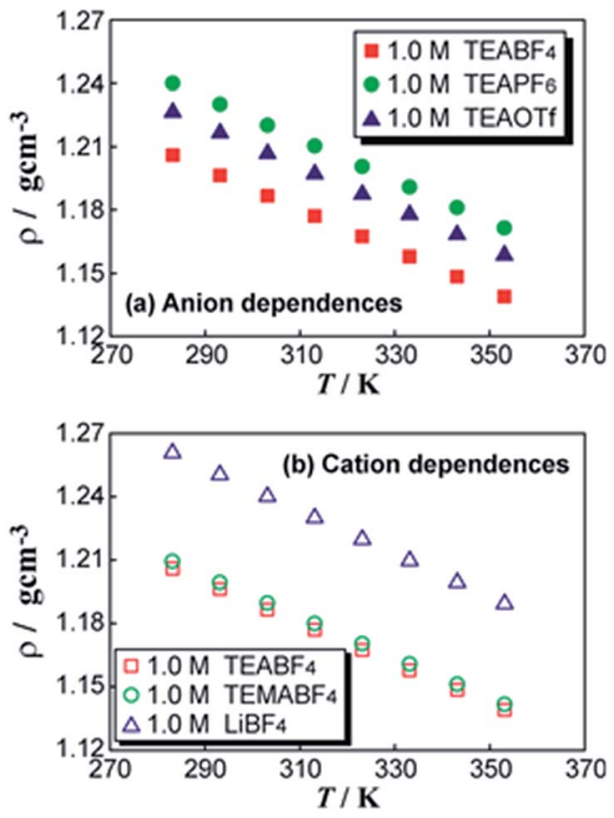

Fig. 5 Comparison of temperature dependence of density $\rho$ for $1.0 \mathrm{M}$ PC-based electrolytes for (a) anions and (b) cations.

samples, the dominant effects on the viscosity were induced by the dissolved salt. The $\eta^{-1}$ values showed good correspondence with $\sigma$ and $D$ values.

Fig. 5 shows the density $\rho$ of the electrolytes as a function of temperature. The $\rho$ values linearly decreased with increase of temperature: $\mathrm{TEABF}_{4}<\mathrm{TEAPF}_{6}<\mathrm{TEAOTf}$ and $\mathrm{TEMABF}_{4} \approx$ $\mathrm{TEABF}_{4}<\mathrm{LiBF}_{4}$. This is also in good agreement with the trend of the $\eta$ values. This implies that an electrolyte with smaller $\rho$ exhibits a lower $\eta$ and higher $D$ owing to the larger space available for the carrier ions to move in the present samples. The observed data for the $\mathrm{LiBF}_{4}$-based electrolyte deviated considerably in $\sigma, \eta^{-1}$ and $\rho$, but not in $D$ values. This means that the interaction in the electrolyte is quite strong for $\mathrm{Li}^{+}$and there is a smaller space for the ions and PC solvent to move than that in the ammonium salt-based electrolytes.

\section{Discussion}

To observe the effect of mobilities $\mu$ of the carrier ions on ionic conductivity $\sigma$, the $\sigma$ values are plotted against the sum of $D_{\text {cation }}$ $+D_{\text {anion }}$ in Fig. 6 for (a) a common $\mathrm{TEA}^{+}$cation with three different anions and (b) a common $\mathrm{BF}_{4}{ }^{-}$anion with three different cations. The $\sigma$ values increased with an increase in $\left(D_{\text {cation }}+D_{\text {anion }}\right)$ for all electrolytes. The cation and anion diffusion constants clearly influence the $\sigma$ values. In the common $\mathrm{TEA}^{+}$systems, the $\sigma$ values depend on the counteranions in the order $\mathrm{BF}_{4}^{-}>\mathrm{PF}_{6}{ }^{-}>\mathrm{OTf}^{-}$, although the ion diffusion constants were slightly modulated by the anions. In the common $\mathrm{BF}_{4}{ }^{-}$systems, the $\sigma$ values are similar in the TEMA- $\mathrm{BF}_{4}$ and TEA-BF ${ }_{4}$ electrolytes, but the TEMA-BF 4 electrolyte exhibited larger $\left(D_{\text {cation }}+D_{\text {anion }}\right)$. The $\mathrm{LiBF}_{4}$ electrolyte showed exceptionally smaller $\sigma$ and $\left(D_{\text {cation }}+D_{\text {anion }}\right)$ values, suggesting different solution structures. The ammonium
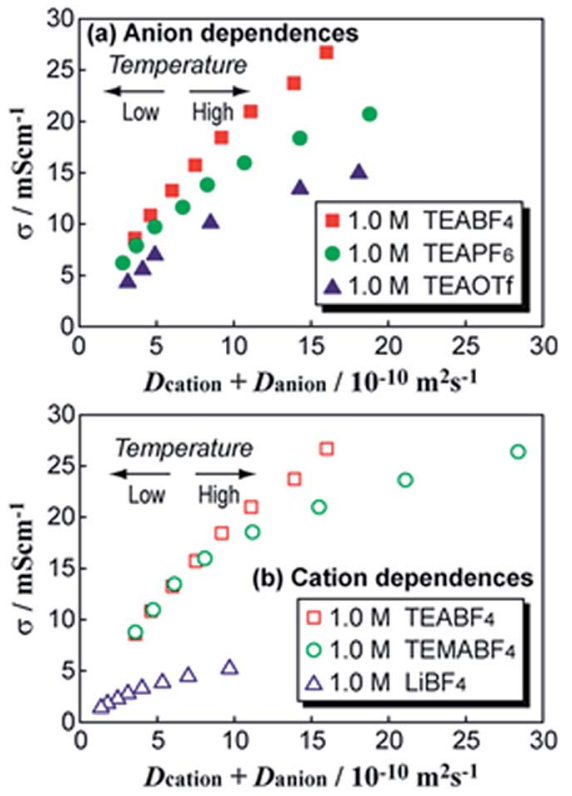

Fig. 6 Plots of ionic conductivity $\sigma$ against the sum of $\left(D_{\text {cation }}+D_{\text {anion }}\right)$ for (a) common TEA ${ }^{+}$with three different anions and (b) common $\mathrm{BF}_{4}{ }^{-}$ with three different cations for 1.0 M PC electrolytes.

cations, especially TEMA ${ }^{+}$, therefore have an advantage from the viewpoint of mobility when compared with $\mathrm{Li}^{+}$.

As mentioned above, ion transport in capacitor electrolytes is considered to occur via a vehicle mechanism. The relationship between $D$ and $\eta$ can therefore be defined by the Stokes-Einstein equation, ${ }^{\mathbf{1 1}}$ as follows:

$$
D=k T / c \pi \eta r_{\text {ion }}
$$

where $k$ is Boltzmann's constant, $T$ is temperature $(\mathrm{K}), \eta$ is viscosity of the electrolyte $\left(\mathrm{Pa} \mathrm{s}^{-1}\right), r_{\text {ion }}$ is the Stokes (solvated ion) radius $(m)$ and $c$ is a constant, which ranges between 4 and 6 for slip and stick boundary conditions, respectively. ${ }^{25}$ Eqn (3) implies that an electrolyte with lower viscosity exhibits higher $D$ value of the solvent. Fig. 7 shows the self-diffusion coefficients of PC, $D_{\mathrm{PC}}$, plotted against $\eta^{-1}$ of the electrolytes. For all electrolytes, $D_{\mathrm{PC}}$ increased with increase of $\eta^{-1}$, according to eqn (3). At high temperatures, deviations from linear plots suggested interactions between PC and the ions.

In eqn (3), $c$ and $\eta$ are assumed to be the same for the ions and PC, so the $r_{\text {ion }} / r_{\mathrm{PC}}$ value is simply defined as eqn (4): ${ }^{22}$

$$
r_{\text {ion }} / r_{\mathrm{PC}}=D_{\mathrm{PC}} / D_{\text {ion }}
$$

The $r_{\text {ion }} / r_{\mathrm{PC}}$ value represents the effective radius of the diffusing ion in the electrolyte because the PGSE-NMR method gives average values of self-diffusion coefficients of the ions and PC. Table 2 shows the relative ion radius relative to PC $\left(r_{\text {ion }} / r_{\mathrm{PC}}\right)$ for the five electrolytes.

Based on their molecular structures, the ionic radii of $\mathrm{TEA}^{+}$, $\mathrm{TEMA}^{+}, \mathrm{Li}^{+}, \mathrm{BF}_{4}{ }^{-}, \mathrm{PF}_{6}{ }^{-}, \mathrm{OTf}^{-}$, and PC were calculated as 0.343 , $0.327,0.076,0.229,0.254,0.270$ and $0.276 \mathrm{~nm}$, respectively. ${ }^{12} \mathrm{In}$ the present study, except for $\mathrm{LiBF}_{4}$, the orders of magnitude of 

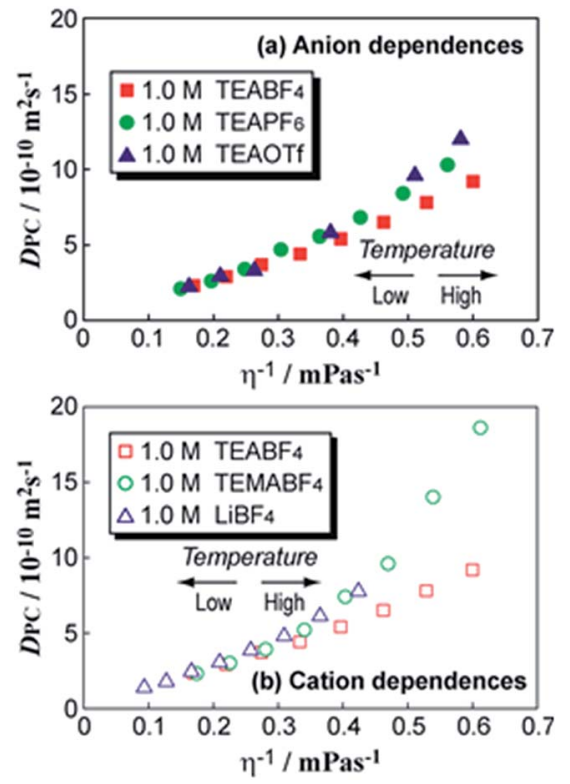

Fig. 7 Plots of solvent self-diffusion coefficients $D_{P C}$ against the inverse of viscosity $\eta^{-1}$ for $1.0 \mathrm{M} \mathrm{PC}$ electrolytes in (a) common TEA TE $^{+}$ with three different anions and (b) common $\mathrm{BF}_{4}{ }^{-}$with three different cations.

Table 2 Ionic radius relative to $\mathrm{PC}\left(r_{\text {ion }} / r_{\mathrm{PC}}\right)$ in the capacitor electrolytes at $303 \mathrm{~K}$, calculated using eqn (4)

\begin{tabular}{llllll}
\hline Species & TEABF $_{4}$ & TEAPF $_{6}$ & TEAOTf & TEMABF $_{4}$ & LiBF $_{4}$ \\
\hline Anion & 1.1 & 1.3 & 1.2 & 1.1 & 1.7 \\
Cation & 1.5 & 1.5 & 1.5 & 1.5 & 2.4
\end{tabular}

the $r_{\text {ion }} / r_{\mathrm{PC}}$ values of the cations and anions calculated from the $D_{\text {ion's }}$ 's agreed relatively well with the estimated values from the van der waals' radii; however, all $r_{\mathrm{ion}} / r_{\mathrm{PC}}$ values were slightly larger than those from the radii, implying the formation of weak solvation structures and ion pairs between the solvent and/or counterions. In contrast, the $r_{\text {ion }} / r_{\mathrm{PC}}$ values of $\mathrm{Li}^{+}$and $\mathrm{BF}_{4}{ }^{-}$in the $\mathrm{LiBF}_{4}$ electrolyte were much larger. This indicates that either $\mathrm{Li}^{+}$interacts strongly with $\mathrm{PC}$ to form a solvated $\mathrm{Li}^{+}(\mathrm{PC})_{x}$ species or that $\mathrm{BF}_{4}{ }^{-}$contributes to the formation of ion pairs. As a result, $\mathrm{Li}^{+}$and $\mathrm{BF}_{4}{ }^{-}$in the electrolyte diffuse more slowly than the ions in the TEA and TEMA electrolytes. In addition, the $r_{\mathrm{Li}} /$ $r_{\mathrm{PC}}$ value of $\mathrm{Li}^{+}$was about 2.4, implying that the number of solvated PC molecules with $\mathrm{Li}^{+}$was in the range of 2 to 4 . In general, it is known that $\mathrm{Li}^{+}$is solvated by $c a$. four PC molecules. ${ }^{26}$ The $r_{\mathrm{Li}} / r_{\mathrm{PC}}$ value obtained by our method therefore includes exchange between molecules in the bulk PC and is in good agreement with the assumed value. In the EDLC electrolytes, the values of $r_{\mathrm{TEA}} / r_{\mathrm{PC}}$ and $r_{\mathrm{TEMA}} / r_{\mathrm{PC}}$ suggest that the ammonium cations interact weakly with PC and/or the counteranions to form weak solvation structures and ion pairs.

As shown by eqn (1), the ionic conductivity of solution electrolytes is also influenced by the number of carrier ions $n$ per specific volume. To clarify the effect of the $n$ on $\sigma$, we
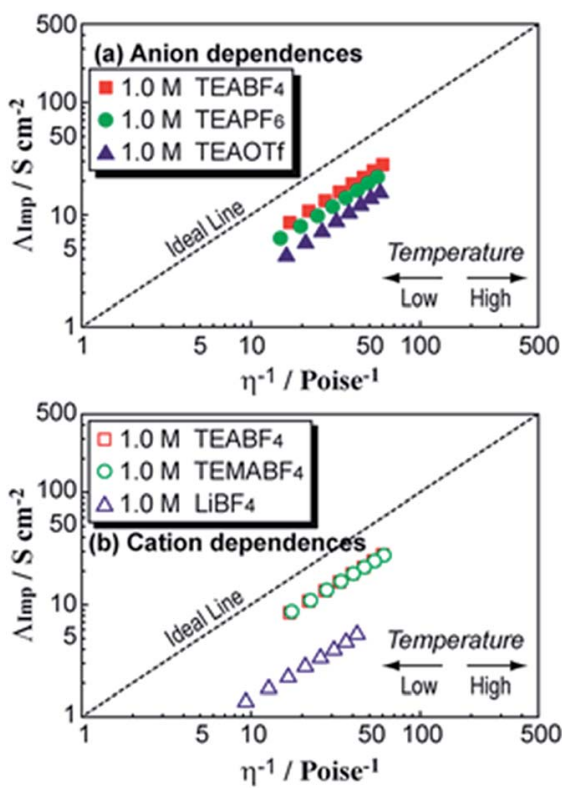

Fig. 8 Walden plots for 1.0 M PC electrolytes for (a) TEA ${ }^{+}$with three different anions and (b) $\mathrm{BF}_{4}{ }^{-}$with three different cations.

conducted analyses using Walden plots and the Nernst-Einstein equation.

Fig. 8 shows the Walden plots for (a) a common $\mathrm{TEA}^{+}$cation and three different anions and (b) a common $\mathrm{BF}_{4}{ }^{-}$anion and three different cations. Here, ionic conductivity $\sigma$ was converted to molar conductivity $\Lambda_{\text {imp }}$ using the densities $\rho$ given in Fig. 5 . The Walden plots deviated downward from the ideal line. In the common $\mathrm{TEA}^{+}$electrolytes (Fig. 8(a)), the deviation became little larger on changing from $\mathrm{BF}_{4}{ }^{-}$to $\mathrm{PF}_{6}{ }^{-}$to OTf ${ }^{-}$, following the anion size. In the common $\mathrm{BF}_{4}{ }^{-}$electrolytes (Fig. 8(b)), the plots of $\mathrm{TEA}^{+}$and $\mathrm{TEMA}^{+}$overlapped, but that for the Li electrolyte deviated considerably.

The molar ionic conductivity $\Lambda_{\mathrm{NMR}}$ can be calculated from the self-diffusion coefficients $\left(D_{+}, D_{-}\right)$by the Nernst-Einstein equation, as follows:

$$
\Lambda_{\mathrm{NMR}}=N e^{2}\left(D_{+}+D_{-}\right) / k T
$$

where $N$ is the number of isolated ions per specific volume. Eqn (5) holds for electrolytes in which ions are perfectly dissociated (such as in an infinite diluted solution). From the $D_{+}$and $D_{-}$ determined by PGSE-NMR measurements, the experimental $\Lambda_{\mathrm{NMR}}$ values were calculated for the five electrolytes. PGSE-NMR data provide the average $D$ values for all ions, including isolated and paired ions. NMR measurements cannot distinguish charged (isolated) ions from paired ions, so the experimental $\Lambda_{\mathrm{NMR}}$ includes whole diffusion species. We have confirmed that at infinite dilution in lithium organic solutions, eqn (5) exactly holds. ${ }^{21}$ In practical electrolytes, the calculated experimental $\Lambda_{\mathrm{NMR}}$ is always larger than $\Lambda_{\mathrm{imp}}$ at all temperatures. The apparent degree of ion dissociation, $\alpha_{\mathrm{app}}$ in solution electrolytes can be determined from eqn (6): $:^{20-22}$

$$
\alpha_{\mathrm{app}}=\Lambda_{\mathrm{imp}} / \Lambda_{\mathrm{NMR}}
$$


Fig. 9 shows the temperature dependences of the $\alpha_{\text {app }}$ values. At $303 \mathrm{~K}$, the $\alpha_{\text {app }}$ is largest for $\mathrm{TEABF}_{4}$, followed by the order $\mathrm{TEABF}_{4}>\mathrm{TEAPF}_{6} \approx \mathrm{TEMABF}_{4}>\mathrm{TEAOTf}_{\mathrm{T}} \mathrm{LiBF}_{4}$. Generally, the $\alpha_{\text {app }}$ values are insensitive to temperature, except for the $\mathrm{TEAPF}_{6}$ and $\mathrm{TEMABF}_{4}$ electrolytes. At a glance, it is a little strange that the degree of ion dissociation decrease in the higher temperatures for $\mathrm{TEAPF}_{6}$ and $\mathrm{TEMABF}_{4}$. At the present stage, however, we cannot clearly explain the reasons why the $\alpha_{\text {app }}$ is insensitive to temperature. More studies are required to interpret the temperature dependent ion-solvent and ion-ion interactions.

The Walden plots and $\alpha_{\text {app }}$ values indicate that ion dissociation is higher for $\mathrm{TEA}^{+}$and $\mathrm{TEMA}^{+}$ammonium salts than that for $\mathrm{LiBF}_{4}$. The magnitude of deviation in the Walden plots agrees with the order of ion dissociation $\alpha_{\text {app }}$ TEABF $_{4}>$ TEAPF $_{6}$ $>$ TEAOTf and $\mathrm{TEABF}_{4} \approx \mathrm{TEMABF}_{4} \gg \mathrm{LiBF}_{4}$. This trend is in good agreement with those estimated from $\Lambda_{\text {imp }}$ and the limiting molar conductivity $\Lambda_{0}$ values reported by Ue et al. ${ }^{\mathbf{1 6}}$ From the number of carrier ions, this order also agreed well with that of $\sigma$. Ionic conductivity of the electrolytes is, therefore also closely related to the concentration of carrier ions.

Mobility and concentration of the carrier ions are strongly related to physical parameters $(\eta, \rho$ and $D)$ and it is necessary to understand the mutual interactions between cation-anion, PCcation and PC-anion. Here, we calculated these three interaction energies $\Delta E$ using DFT and HSAB calculations. ${ }^{\mathbf{1 6 - 1 8}}$ When an interaction occurs, for example, between M1 and M2, the change in the total energy, $\Delta E$, and the number $\Delta N$ of electrons transferring from M1 to M2, are represented by eqn (7) and (8), as given by Pearson et al.::27,28

$$
\Delta E=-\left(\chi_{\mathrm{M} 1}-\chi_{\mathrm{M} 2}\right)^{2} / 4\left(\eta_{\mathrm{M} 1}+\eta_{\mathrm{M} 2}\right)
$$
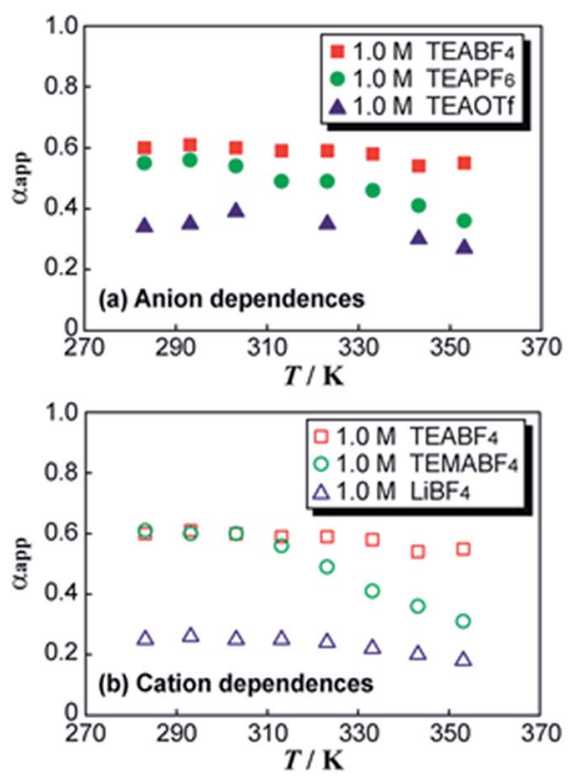

Fig. 9 Plots of degree of dissociation $\alpha_{\text {app }}$ for 1.0 M PC electrolytes as a function of temperature for (a) common $\mathrm{TEA}^{+}$with three different anions and (b) common $\mathrm{BF}_{4}{ }^{-}$with three different cations.

$$
\Delta N=\left(\chi_{\mathrm{M} 1}-\chi_{\mathrm{M} 2}\right) / 2\left(\eta_{\mathrm{M} 1}+\eta_{\mathrm{M} 2}\right)
$$

where $\chi$ and $\eta$ refer to the absolute electronegativity and absolute hardness of M1 and M2 without interactions, respectively. $\chi$ and $\eta$ are calculated by eqn (9) and (10), respectively:

$$
\begin{gathered}
\chi=(I+A) / 2 \\
\eta=(I-A) / 2
\end{gathered}
$$

where $I$ and $A$ respectively refer to the ionization potential and electron affinity between the interacting species. $I$ and $A$ are calculated by eqn (11) and (12), respectively:

$$
\begin{aligned}
& I=E\left(\mathrm{X}^{1+}\right)-E\left(\mathrm{X}^{0}\right) \\
& A=E\left(\mathrm{X}^{0}\right)-E\left(\mathrm{X}^{1-}\right)
\end{aligned}
$$

where $E\left(\mathrm{X}^{0}\right)$ refers to the total energy of the interacting species and $E\left(\mathrm{X}^{1-}\right)$ and $E\left(\mathrm{X}^{1+}\right)$ refer to ions having -1 and +1 electrons, respectively. The total energies, $E\left(\mathrm{X}^{0}\right), E\left(\mathrm{X}^{1-}\right)$ and $E\left(\mathrm{X}^{1+}\right)$, and the estimated $\chi$ and $\eta$ of the cations and anions are summarized in Table 3. According to the HSAB theory, if $\chi$ is higher, the ions and solvent are stronger Lewis acids; if $\chi$ is lower, the chemical species is a stronger Lewis base. In addition, a "hard" Lewis acid prefers to interact with a "hard" Lewis base, and a "soft" Lewis acid prefers to interact with a "soft" Lewis base. As shown in Table 3, $\mathrm{TEA}^{+}$and $\mathrm{TEMA}^{+}$exhibited smaller $\chi$ values (8.96 and 9.00, respectively) than $\mathrm{Li}^{+}$(40.8), indicating that they are weaker Lewis acids.

TEA $^{+}$and TEMA $^{+}$therefore weakly interact with anions as Lewis bases, compared with $\mathrm{Li}^{+}$, as shown in Table 4. In contrast, the hardnesses $\eta$ of $\mathrm{TEA}^{+}$and $\mathrm{TEMA}^{+}$were smaller (6.42 and 6.46, respectively) than that of $\mathrm{Li}^{+}(35.2)$, so TEA ${ }^{+}$and TEMA $^{+}$prefer to interact with the "soft" Lewis base anion OTf (5.00). The orders of magnitude for $\Delta E$ and $\Delta N$ are $\mathrm{LiBF}_{4}>$ TEAOTf $>\mathrm{TEMABF}_{4} \approx \mathrm{TEABF}_{4}>\mathrm{TEAPF}_{6}$, which means that $\mathrm{TEAPF}_{6}$ and $\mathrm{TEABF}_{4}$ possess an advantage for the dissociation for their salts.

Considering the solvation energy of ions by PC, $\Delta E$ and $\Delta N$ for the PC-cation and PC-anion interactions are summarized in Table 5. In general, the $\Delta E$ of $\mathrm{Li}^{+}-\mathrm{PC}$ is quite large $(-7.94 \mathrm{eV})$, which stabilizes the solvation structure. For the $\mathrm{TEA}^{+}$and TEMA $^{+}$salts, the PC-cation $\Delta E$ is quite small $(-0.35$ and $-0.36 \mathrm{eV}$, respectively), which is less than $1 / 20$ of that of $\mathrm{PC}-\mathrm{Li}^{+}$.

Table 3 Absolute electronegativity and absolute hardness of cations, anions and PC solvent

\begin{tabular}{llllcc}
\hline Species & $E\left(\mathrm{X}^{1-}\right) / \mathrm{au}$ & $E\left(\mathrm{X}^{0}\right) / \mathrm{au}$ & $E\left(\mathrm{X}^{1+}\right) / \mathrm{au}$ & $\chi / \mathrm{eV}$ & $\eta / \mathrm{eV}$ \\
\hline $\mathrm{TEA}^{+}$ & -371.620711 & -371.527501 & -370.962229 & 8.96 & 6.42 \\
$\mathrm{TEMA}^{+}$ & -332.294914 & -332.201415 & -331.633078 & 9.00 & 6.46 \\
$\mathrm{Li}^{+}$ & -7.49133310 & -7.28491780 & -4.49025230 & 40.8 & 35.2 \\
$\mathrm{BF}_{4}{ }^{-}$ & -424.480287 & -424.679695 & -424.410189 & 0.954 & 6.38 \\
$\mathrm{PF}_{6}{ }^{-}$ & -940.707423 & -940.896614 & -940.597012 & 1.50 & 6.65 \\
$\mathrm{OTf}^{-}$ & -961.555515 & -961.730421 & -961.537879 & 0.240 & 5.00 \\
PC & -381.808186 & -381.835289 & -381.452645 & 4.84 & 5.57
\end{tabular}


Table 4 Interaction energy $\Delta E$ and number of electrons transferred $\Delta N$ between cations and anions of the salts ${ }^{a}$

\begin{tabular}{lll}
\hline Interaction & $\Delta E / \mathrm{eV}$ & $\Delta N$ \\
\hline $\mathrm{BF}_{4}{ }^{-} \rightarrow \mathrm{TEA}^{+}$ & -1.25 & 0.313 \\
$\mathrm{PF}_{6}{ }^{-} \rightarrow \mathrm{TEA}^{+}$ & -1.06 & 0.285 \\
$\mathrm{OTf}^{-} \rightarrow \mathrm{TEA}^{+}$ & -1.66 & 0.382 \\
$\mathrm{BF}_{4}{ }^{-} \rightarrow \mathrm{TEMA}^{+}$ & -1.26 & 0.314 \\
$\mathrm{BF}_{4}{ }^{-} \rightarrow \mathrm{Li}^{+}$ & -9.56 & 0.479
\end{tabular}

${ }^{a} \Delta E$ and $\Delta N$ correspond to changes in total energy and number of transferred electrons for each interaction, respectively. The arrows show the direction of electron transfer.

Table 5 Interaction energy $\Delta E$ and number of electrons transferred $\Delta N$ between $\mathrm{PC}-$ cation and $\mathrm{PC}-$ anion $^{a}$

\begin{tabular}{lll}
\hline Interaction & $\Delta E / \mathrm{eV}$ & $\Delta N$ \\
\hline $\mathrm{PC} \rightarrow \mathrm{TEA}^{+}$ & -0.354 & 0.172 \\
$\mathrm{PC} \rightarrow \mathrm{TEMA}^{+}$ & -0.361 & 0.173 \\
$\mathrm{PC} \rightarrow \mathrm{Li}^{+}$ & -7.94 & 0.441 \\
$\mathrm{PC} \rightarrow \mathrm{BF}_{4}^{-}$ & -0.315 & 0.162 \\
$\mathrm{PC} \rightarrow \mathrm{PF}_{6}^{-}$ & -0.227 & 0.136 \\
$\mathrm{PC} \rightarrow \mathrm{OTf}^{-}$ & -0.500 & 0.217
\end{tabular}

${ }^{a} \Delta E$ and $\Delta N$ correspond to changes in total energy and number of electrons transferred for each interaction, respectively. The arrows show the direction of electron transfer.

$\Delta E$ of the PC-anion interaction was almost same. In addition, $\Delta E$ values for the dissociation energies of the salts were also smaller (from -1.06 for $\mathrm{TEABF}_{4}$ to $-1.66 \mathrm{eV}$ for TEAOTf) than that of $\mathrm{LiBF}_{4}(-9.56 \mathrm{eV})$. The ammonium salts were, therefore dissociated by interaction between the species. As a result, ammonium cations do not form strong solvation structures as do $\mathrm{Li}^{+}$-based electrolytes. This leads to electrolytes exhibiting higher $\mu$ and $n$ for enhancement of ionic conductively $\sigma$ : the weak Lewis acidity of TEA ${ }^{+}$and TEMA ${ }^{+}$provides the high $\alpha_{\text {app }}$ of these salts to increase $n$ in the EDLC electrolytes. Consequently, the $\mathrm{TEABF}_{4}$ salt was most highly dissociated in PC, and the TEA ${ }^{+}$ and $\mathrm{BF}_{4}{ }^{-}$ions and $\mathrm{PC}$ solvent were relatively freely move towards each other in the electrolytes. We therefore have to find an optimum combination of much "softer" and "weaker" Lewis acid cations and much "harder" and "weaker" Lewis base anions to improve the salt dissociation, which will lead to an increase in the number of carrier ions in the capacitor electrolytes. The ionic radii of the cation and anion are also important for capacitor electrolytes because of the relatively weak solvation by $\mathrm{PC}$ compared with that in $\mathrm{Li}^{+}$electrolytes, such as $1.0 \mathrm{M}$ $\mathrm{LiPF}_{6} / \mathrm{EC}+$ DEC for $\mathrm{LICs}^{15}$ and LIBs. ${ }^{23}$

\section{Conclusions}

In this study, we discussed ion transport in $1.0 \mathrm{M}$ PC capacitor electrolytes comprising of five salts, i.e., TEABF $4, \mathrm{TEAPF}_{6}$, TEAOTf, $\mathrm{TEMABF}_{4}$ and $\mathrm{LiBF}_{4}$. The mobility of individual ions and PC was determined by self-diffusion coefficients $D$ measured by PGSE-NMR. The TEABF 4 electrolyte exhibited the highest $D$ and $\sigma$ and the lowest $\eta$, indicating highest mobility $\mu$ of the carrier ions. We also estimated the apparent salt dissociation degree, $\alpha_{\text {app }}$ by comparing $\Lambda_{\mathrm{imp}}$ and $\Lambda_{\mathrm{NMR}}$. The TEABF salt exhibited the highest $\alpha_{\text {app }}$ among these PC electrolytes in the temperature range from 283 to $353 \mathrm{~K}$. Ion dissociation was shown to have close relations with the Lewis acidity of the cations and Lewis basicity of the anions, under the influence of the hardness and softness of the ions. The target samples of this study are electrolyte systems for electric double layer capacitors, and the salt concentration is relatively low. The experimental findings showed the importance of the quaternary ammonium$\mathrm{BF}_{4}$ electrolytes which are currently used in practical EDLC. All the data obtained in this study give sufficient consistency with ionic conductivity. The obtained physical parameters explained the mobility $\mu$ and number $n$ of carrier ions in terms of solvation and ion pairs. Control of Lewis acidity and basicity is an important factor to design electrolytes for new-generation electrochemical capacitors. We are undertaking further investigations using new ionic species, such as cyclic cation (spirotype) salts and low-melting-point salts (ionic liquids), and other solvents, such as acetonitrile towards better systems, based on the concepts in this study.

\section{Acknowledgements}

This work was supported by MEXT's scientific technology human resource development grant, "Program to Disseminate Tenure Tracking System,” Japan.

\section{References}

1 A. D. Pasquier, I. Plitz, S. Menocal and G. G. Amatucci, J. Power Sources, 2003, 115, 171.

2 A. D. Pasquier, I. Plitz, J. Gural, F. Badway and G. G. Amatucci, J. Power Sources, 2004, 136, 160.

3 A. G. Pandolfo and A. F. Hollenkamp, J. Power Sources, 2006, 157, 11.

4 A. Burke, Electrochim. Acta, 2007, 53, 1083.

5 P. Simon and Y. Gogoti, Nat. Mater., 2008, 7, 845.

6 G. G. Amatucci, F. Badway, A. D. Pasquier and T. Zheng, J. Electrochem. Soc., 2001, 148, A930.

7 A. D. Pasquier, A. Laforgue, P. Simon, G. G. Amatucci and J.-F. Fauvarque, J. Electrochem. Soc., 2002, 149, A302.

8 J. R. Dhan and J. A. Seel, J. Electrochem. Soc., 2000, 147, 899. 9 A. Yoshino, T. Tsubata, M. Shimoyamada, H. Satake, Y. Okano, S. Mori and S. Yata, J. Electrochem. Soc., 2004, 151, A2180.

10 K. Naoi and P. Simon, Electrochem. Soc. Interface, 2008, 17, 34.

11 K. Naoi, S. Ishimoto, J. Miyamoto and W. Naoi, Energy Environ. Sci., 2012, 5, 9363.

12 M. Ue, K. Ida and S. Mori, J. Electrochem. Soc., 1994, 141, 2989.

13 M. Ue, Electrochemistry, 2007, 75(8), 565.

14 K. Chiba, T. Ueda and H. Yamamoto, Electrochemistry, 2007, 75(8), 664. 
15 C. Zhong, Y. Deng, W. Hu, J. Qiao, L. Zhang and J. Zhang, Chem. Soc. Rev., 2015, 44, 7484.

16 M. Ue, J. Electrochem. Soc., 1994, 141, 3336.

17 R. G. Pearson, J. Chem. Educ., 1968, 45, 581-643.

18 Density-Functional Theory of Atoms and Molecules, ed. R. G. Parr and W. Yang, Oxford University Press, Oxford, UK, 1989.

19 M. Saito, H. Ikuta, Y. Uchimoto and M. Wakihara, J. Phys. Chem. B, 2003, 107, 11608.

20 K. Hayamizu, Y. Aihara, S. Arai and C. G. Martinez, J. Phys. Chem. B, 1999, 103, 519.

21 Y. Aihara, K. Sugimoto, W. S. Price and K. Hayamizu, J. Chem. Phys., 2000, 113, 1981.

22 K. Hayamizu, E. Akiba, T. Banno and Y. Aihara, J. Chem. Phys., 2002, 117, 5929.

23 K. Hayamizu, J. Chem. Eng. Data, 2012, 57, 2012.

24 M. J. Frisch, G. W. Trucks, H. B. Schlegel, G. E. Scuseria, M. A. Robb, J. R. Cheeseman, G. Scalmani, V. Barone, B. Mennucci, G. A. Petersson, H. Nakatsuji, M. Caricato, X. Li, H. P. Hratchian, A. F. Izmaylov, J. Bloino, G. Zheng, J. L. Sonnenberg, M. Hada, M. Ehara, K. Toyota, R. Fukuda, J. Hasegawa, M. Ishida, T. Nakajima, Y. Honda,
O. Kitao, H. Nakai, T. Vreven, J. A. Montgomery Jr, J. E. Peralta, F. Ogliaro, M. Bearpark, J. J. Heyd, E. Brothers, K. N. Kudin, V. N. Staroverov, R. Kobayashi, J. Normand, K. Raghavachari, A. Rendell, J. C. Burant, S. S. Iyengar, J. Tomasi, M. Cossi, N. Rega, J. M. Millam, M. Klene, J. E. Knox, J. B. Cross, V. Bakken, C. Adamo, J. Jaramillo, R. Gomperts, R. E. Stratmann, O. Yazyev, A. J. Austin, R. Cammi, C. Pomelli, J. W. Ochterski, R. L. Martin, K. Morokuma, V. G. Zakrzewski, G. A. Voth, P. Salvador, J. J. Dannenberg, S. Dapprich, A. D. Daniels, Ö. Farkas, J. B. Foresman, J. V. Ortiz, J. Cioslowski and D. J. Fox, Gaussian 09, Revision B.01, Gaussian, Inc., Wallingford CT, 2009.

25 H. Evey, A. G. Bishop, M. Forsyth and D. R. MacFarlane, Electrochim. Acta, 2000, 45, 1279.

26 M. Morita, Y. Asai, N. Yoshimoto and M. Ishikawa, J. Chem. Soc., Faraday Trans., 1998, 94, 3451.

27 R. G. Parr and R. G. Pearson, J. Am. Chem. Soc., 1983, 105, 7512.

28 R. G. Pearson, Inorg. Chem., 1984, 23, 4675. 